\title{
The Role of Bamboo Shoot Gigantochloa Apus Extract in Decreasing the IL-17/IL-10 Ratio Level in the Atherosclerosis Process
}

\author{
Edy Soesanto ${ }^{1 *(\mathbb{D})}$, Satriya Pranata ${ }^{2}$ (D) Sri Rejeki ${ }^{1}$, Lalu Muhammad Irham ${ }^{3}$ (D) \\ ${ }^{1}$ Department of Nursing, Faculty of Nursing and Health Sciences, Universitas Muhammadiyah Semarang, Central Java, \\ Semarang, Indonesia; ' School of Nursing, National Taipei University of Nursing and Health Sciences, Taipei City 112, Taiwan; \\ ${ }^{3}$ Department of Pharmacology and Clinical Pharmacy, Faculty of Pharmacy, Universitas Ahmad Dahlan, Yogyakarta, Indonesia
}

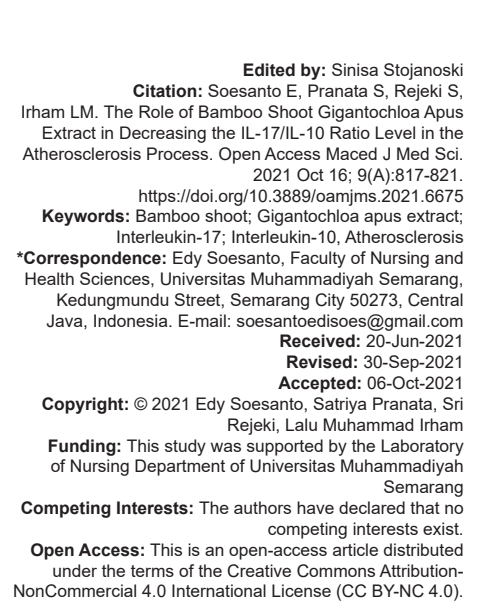

\section{Abstract}

BACKGROUND: Atherosclerosis begins with injury to the endothelial, progressive, and increases by $3 \%$ per year since the age of a person passes 20 years. The ratio of the number of pro and anti-inflammatory cytokines can describe the development of the process of atherosclerosis so that the higher the ratio will increase the chance of atherosclerosis.

AIM: The purpose of this study was to examine the effect of Bamboo shoot Gigantochloa apus (BSGA) extract on decreasing interleukin-17 (IL-17)/IL-10 level ratios in New Zealand White rabbits given an atherogenic diet.

METHODS: This study uses BSGA extract freeze-dried aged 1-2 weeks and New Zealand White rabbits. Atherogenic feed uses $0.5 \%$ egg yolk and $5 \%$ pork oil which is added to the standard feed. Randomized pre- and post-test with control group design by dividing into four groups were used in this study.

RESULTS: The mean ratio of IL-17 levels with IL-10 between before and after $(p<0.005)$ in all groups showed a significant difference. There was a trend of increasing the ratio between IL-17 levels and IL-10 in all groups and the highest increase occurred in the control group which was $420 \%$.

CONCLUSION: The higher the dose of BSGA extract administration could reduce the ratio between IL-17 levels and IL-10 and there is a correlation with a negative linear pattern between IL-10 and IL-17 with $p=0.034$ which means that higher levels of IL-10 will reduce IL-17 levels.

\section{Introduction}

In 2020, the number one death in the world is thought to occur due to cardiovascular disease [1]. Cardiovascular disease is often caused by atherosclerosis. Atherosclerosis is a progressive disease, and increases by $3 \%$ per year since the age of a person goes through 20 years [2]. Inflammation has an important role in the atherosclerosis process. The inflammatory process that occurs in atherosclerosis is triggered by an increase in lipoprotein oxidation so that the process of initiation and acceleration of arterial lesions occurs and stimulates inflammatory molecules, chemotaxis factors in monocytes, stimulates inflammatory signals of endothelial cells, platelets, and T-cell lymphocytes [3]. Low-density lipoprotein (LDL) oxidation triggers an inflammatory response, response Inflammation secretes inflammatory markers such as: Pro-inflammatory cytokines which accelerate the formation of lesions and affect the stability of atherosclerotic plaque which increases the risk of rupture and anti-inflammatory cytokines which are atopic protective and increase plaque stability, inhibit activation of pro-inflammatory cytokine synthesis and inhibits the infiltration of neutrophils and macrophages in the atherosclerotic process [4], [5]. The ratio of the number of pro and anti-inflammatory cytokines can describe the development of the process of atherosclerosis so that the higher the ratio will increase the chances of atherosclerosis [6], [7].

Efforts that can be done to inhibit or prevent the occurrence of inflammatory processes in atherosclerotic diseases include using antioxidants. Antioxidants inhibit LDLoxidation in lesions by reducing oxidative degradation due to nitric oxide, reducing oxidized LDL toxicity to endothelial cells, smooth muscle cells and macrophages, endothelial vascular cell adhesion molecule-1 (VCAM-1) secretion, limiting vasoconstriction, and reducing blood pressure. One of the exogenous antioxidants that is thought to be able to inhibit the inflammatory process in atherosclerosis and has been used by the community as food and medicine is bamboo shoots or young shoots from Bamboo shoot Gigantochloa apus (BSGA) [8]. To prove the effect of BSGA extract on the decrease in the 
ratio between pro-inflammatory cytokines (interleukin-17 [IL-17]) and anti-inflammatory cytokines (IL-10) in New Zealand White rabbits given atherogenic diets was the purpose of this study.

\section{Materials and Methods}

The ingredients used were BSGA extract from Banyumeneng village in Mranggen sub-district Indonesia that were 1-2 weeks old from and dried using dried freeze method and using $90 \%$ ethanol [9]. Its nutritional content every $100 \mathrm{~g}$ consists of $5 \%$ fat, $18 \%$ protein, $14 \%$ crude fiber, $1 \%$ calcium, $0.8 \%$ phosphorus, $12 \%$ ash content, and $12 \%$ moisture content from PT. Chargil Indonesia. Feed is given a maximum of $5 \%$ of the rabbit's body weight (BW) and drinks are given a maximum of $10 \%$ of the rabbit's BW.

The atherogenic feed used is a standard feed supplemented with cholesterol made from $0.5 \%$ egg yolk and $5 \%$ pork oil supplemented with a standard $100 \%$ feed. Cholesterol flour is made from chicken egg yolks dried in an oven at $60^{\circ} \mathrm{C}$ for $24 \mathrm{~h}$ to dry and blend until smooth [10]. The experimental animals used were 4 months old New Zealand White rabbits weighing between 2000 and $2500 \mathrm{~g}$, male sex. Standard feed and atherogenic feed were given as much as $100 \mathrm{~g} /$ day/head and drinking was carried out ad libitum for all rabbits and given every day during the study. Examination of $\mathrm{IL}-17$ and $\mathrm{IL}-10$ used quantitative sandwich enzyme immunoassay technique conducted at the Gajah Mada University Yogyakarta Integrated Research and Testing Laboratory (LPPT).

This study uses pure experimental design, with Randomized pre- and post-test design with control group and has received approval from the Health Research Animal Ethics Commission 23/EC/H/ FK/-RSDK/207 FK UNDIP and RSUP Dr. Kariadi Semarang, Indonesia. 24 rabbits used and divided into four groups. The control group was only given an atherogenic diet then atherogenic diet plus BSGA extract with a concentration of 130,260 , and $520 \mathrm{mg} / \mathrm{kg}$ BW was subsequently given in the treatment Groups I, II, and III. SPSS analysis used paired t-test to find out the difference between mean values before and after treatment, and One-way ANOVA test to determine the difference between the mean values of each group before and after treatment.

\section{Results}

The occurrence of the inflammatory process in atherosclerosis cannot be separated from the role of cytokines both pro-inflammatory cytokines (IL-17) and anti-inflammatory cytokines (IL-10). An increasing in levels of anti-inflammatory cytokines (IL-10) will have an impact on the decrease in the level of proinflammatory cytokines (IL-17) so able to suppress or inhibit the process of atherosclerosis. Thus, the ratio between pro-inflammatory cytokines and antiinflammatory cytokines can also describe the process of atherosclerosis the higher the ratio will increase the chance of atherosclerosis, this is shown in Table 1.

Table 1: Average ratio of IL-17 levels with IL-10 (pg/ml)

\begin{tabular}{|c|c|c|c|c|c|}
\hline Treatment & C & T 1 (130 mg) & T 2 (260 mg) & T 3 (520 mg) & $p$ \\
\hline Before & $0.05 \pm 0.025^{\mathrm{a}}$ & $0.06 \pm 0.018^{\mathrm{a}}$ & $0.16 \pm 0.135^{\mathrm{a}}$ & $0.24 \pm 0.066^{a}$ & $0.002^{1}$ \\
\hline After & $\begin{array}{l}0.26 \pm 0.131^{a} \\
p^{2}=0.028\end{array}$ & $\begin{array}{l}0.04 \pm 0.020^{b} \\
p^{2}=0.0001\end{array}$ & $\begin{array}{l}0.04 \pm 0.110^{b} \\
p^{2}=0.028\end{array}$ & $\begin{array}{l}0.05 \pm 0.019^{b} \\
p^{2}=0.001\end{array}$ & $\begin{array}{l}0.011^{1} \\
p^{3}=0.253\end{array}$ \\
\hline
\end{tabular}

The average ratio between $\mathrm{IL}-17$ levels with IL-10 throughout the sample before treatment was $0.1274 \pm 0.106 \mathrm{pg} / \mathrm{mL}$ with a range of 0.04 $0.41 \mathrm{pg} / \mathrm{mL}$. The average ratio between IL-17 levels with IL-10 throughout the sample after treatment was $0.1113 \pm 0.119 \mathrm{pg} / \mathrm{mL}$ with a range of $0.02-0.44 \mathrm{pg} / \mathrm{mL}$.

The ratio of IL-17 levels with IL-10 throughout the sample before treatment had a significantly different mean value $(p=0.002)$. The ratio of IL-17 levels with IL-10 before treatment in the control group had a lower mean value than the treatment Group $1(130 \mathrm{mg} / \mathrm{kg}$ BW/day) with the lowest value of $0.04 \mathrm{ng} / \mathrm{mL}$ and the highest value of $0.10 \mathrm{ng} / \mathrm{mL}$ with the distribution of data not normally distributed $(p=0.006)$. The ratio of IL-17 levels with IL-10 before treatment in treatment Group 1 (130 mg/kg BW/day) had a lower mean value than treatment Group 2 (260 mg/kg BW/day) with the lowest value of $0.04 \mathrm{ng} / \mathrm{mL}$ and the highest value is $0.09 \mathrm{ng} / \mathrm{mL}$ with a normal distribution of data $(p=0.595)$. The ratio of IL-17 levels with IL-10 before treatment in treatment Group 2 (260 mg/kg BW/day) had a lower average value than the treatment Group $3(520 \mathrm{mg} / \mathrm{kg}$ $\mathrm{BW} /$ day) the lowest value of $0.06 \mathrm{ng} / \mathrm{mL}$ and the highest value is $0.41 \mathrm{ng} / \mathrm{mL}$ with a normal distribution of data $(p=0.061)$. While the ratio of IL-17 levels with IL-10 before treatment in treatment Group $3(520 \mathrm{mg} / \mathrm{kg}$ BW/ day) had the lowest value of $0.14 \mathrm{ng} / \mathrm{mL}$ and the highest value was $0.33 \mathrm{ng} / \mathrm{mL}$ with the distribution of normal distributed data $(p=0.905)$.

Different results with the One-way ANOVA test showed that there was an effect/effect of treatment on the ratio of IL-17 levels with IL-10 before meaningful treatment $(p=0.002)$. Post hoc test analysis showed that couples who had different mean ratios of IL-17 levels with IL-10 before significant treatment were: Control group and treatment Group 2 (260 mg/kg BW/day) with $\mathrm{p}=0.016$, treatment Group 1 (130 mg/kg BW/day) and treatment Group 2 (260 mg/kg BW/day) with $p=0.037$, treatment Group 1 (130 mg/kg BW/day) and treatment Group 3 (520 mg/kg BW/day) with $p=0.004$.

The ratio of $\mathrm{IL}-17$ levels with $\mathrm{IL}-10$ after treatment in all groups had significantly different 
mean values $(p=0.011)$. The ratio of IL-17 levels with IL-10 after treatment in the control group had a higher average value than treatment Group $1(130 \mathrm{mg} / \mathrm{kg}$ $\mathrm{BW} /$ day), the lowest value was $0.14 \mathrm{ng} / \mathrm{mL}$ and the highest value was $0.44 \mathrm{ng} / \mathrm{mL}$ with the distribution of data with normal distribution $(p=0.154)$. The ratio of IL-17 levels with IL-10 after treatment in treatment Group 1 (130 mg/kg BW/day) had a higher average value than treatment Group 2 (260 mg/kg BW/day), the lowest value was $0.02 \mathrm{ng} / \mathrm{mL}$, and the highest value is $0.07 \mathrm{ng} / \mathrm{mL}$ with a normal distribution of data $(p=0.939)$. IL-17 levels ratio with IL-10 after treatment in treatment Group2(260mg/kgBW/day)hadalowermeanvaluethan treatment Group 3 (520 mg/kg BW/day), the lowest value of $0.02 \mathrm{ng} / \mathrm{mL}$ and the highest value is $0.30 \mathrm{ng} / \mathrm{mL}$ with the distribution of data not normally distributed ( $p=$ 0.024). Whereas the IL-17 level ratio with IL-10 after treatment in treatment Group $3(520 \mathrm{mg} / \mathrm{kg}$ BW/day) had the lowest value of $0.02 \mathrm{ng} / \mathrm{mL}$ and the highest value of $0.07 \mathrm{ng} / \mathrm{mL}$ with normal distribution of data $(p=0.833)$.

Different results with the One-way ANOVA test showed that there was an effect/effect of treatment on the ratio of $\mathrm{IL}-17$ levels with $\mathrm{IL}-10$ after meaningful treatment $(p=0.011)$. Post hoc test analysis showed that couples who had different mean ratios of IL-17 levels with IL-10 after significant treatment were: Control group and treatment Group 1 (130 mg/kg BW/day) with $p=0.004$, control group and group treatment 2 (260 mg/kg BW/ day) with $p=0.037$, control group and treatment Group 3 (520 mg/kg BW/day) with $p=0.004$.

The difference or change in the ratio of $\mathrm{IL}-17$ levels with IL-10 between before and after treatment in all groups had significantly different mean values $(p=0.001)$. The difference or change in the ratio of IL-17 levels with IL-10 between before and after treatment in the control group had a higher average value than treatment Group 1 (130 mg/kg BW/day), the lowest value was $0.10 \mathrm{ng} / \mathrm{mL}$ and the highest value $0.35 \mathrm{ng} / \mathrm{mL}$ with normal distribution of data $(p=0.084)$. Difference or change in the ratio of IL-17 levels with IL-10 between before and after treatment in treatment Group 1 (130 mg/kg BW/day) has a higher average value than treatment Group 2 (260 mg/ $\mathrm{kg} \mathrm{BW} /$ day), the lowest value $-0.02 \mathrm{ng} / \mathrm{mL}$ and the highest value of $-0.01 \mathrm{ng} / \mathrm{mL}$ with the distribution of data not normally distributed $(p=0.033)$. The difference or change in the ratio of IL-17 levels with IL-10 between before and after treatment in treatment Group 2 (260 mg/ $\mathrm{kg} \mathrm{BW/day)} \mathrm{had} \mathrm{a} \mathrm{higher} \mathrm{average} \mathrm{value} \mathrm{than} \mathrm{treatment}$ Group 3 (520 mg/ kg BW/day), the lowest value $-0.11 \mathrm{ng} / \mathrm{mL}$ and the highest value of $-0.03 \mathrm{ng} / \mathrm{mL}$ with the distribution of data normally distributed ( $p=0.687$ ). While, the difference or change in the ratio of IL-17 levels with IL-10 between before and after treatment in treatment Group 3 (520 mg/kg BW/day) had the lowest value of $-0.27 \mathrm{ng} / \mathrm{mL}$ and the highest value of $-0.10 \mathrm{ng} / \mathrm{mL}$ with normal distribution of data $(p=0.974)$.
Different results with the One-way ANOVA test showed that there was an effect/effect of treatment on the difference or change in the ratio of IL-17 levels with IL-10 between before and after the treatment which was significant $(p=0.001)$. Post hoc test analysis found that all couples had different mean differences or changes in the ratio of IL-17 levels with IL-10 between before and after a meaningful treatment, so it can be concluded that all treatments can prevent elevated levels of IL-17 levels with IL- 10 .

\section{Discussion}

The effect of treatment on changes in the mean value of IL-10 levels with IL-10 levels is known by performing a mean difference test before and after treatment. This analysis uses two types of paired sample different tests, namely, paired t-test. The results showed that by using a paired different test (pre-post) showed that there were significant differences in the mean ratio of IL-17 levels with IL-10 between before and after $(p<0.005)$ in all groups. In Table 1, it can also be seen that there was a trend of increasing the ratio between IL-17 levels with IL-10 in all groups and the highest increase occurred in the control group which was $420 \%$, the higher the rabbit got BSGA extract (treatment Group $3=520 \mathrm{mg} /$ $\mathrm{kg} \mathrm{BW/day)} \mathrm{the} \mathrm{ratio} \mathrm{between} \mathrm{IL-17} \mathrm{and} \mathrm{IL-10} \mathrm{levels} \mathrm{will}$ decrease. The highest difference between the IL-17 and IL-10 levels was in the control group and the lowest was in treatment Group 3 (520 mg/kg BW/day) so that a dose effect relationship reduced the ratio between IL-17 levels and IL-10 is $520 \mathrm{mg} / \mathrm{kg} \mathrm{BW/day.}$

This study suggests that the application of BSGA extract in various doses to New Zealand White rabbits given atherogenic diet was able to reduce the IL-17/IL-10 ratio, so that the administration of BSGA extract had an influence on the ratio between $\mathrm{IL}-17$ levels with IL-10, and prove that the higher dosage of BSGA extract administration will reduce the ratio between IL-17 levels and IL-10.

Furthermore, this study illustrates that there is a trend of an increase in the ratio between IL-17 levels with IL-10 in all groups and the highest increasing trend occurs in the control group which is $420 \%$. The highest difference between the IL-17 and IL-10 levels occurred in the control group and the lowest was in the treatment Group $3(520 \mathrm{mg} / \mathrm{kg}$ BW/ day) so that the administration of BSGA extract had an influence on the ratio between IL-17 levels and IL -10, and prove that the higher dosage of BSGA extract administration will reduce the ratio between $\mathrm{IL}-17$ levels with IL-10 and there is a correlation between a negative linear pattern between IL-10 and IL-17 with a $p=0.034$ means that the higher the level IL-10 will reduce IL-17 levels. 
High levels of pro-inflammatory cytokines will stimulate the expression of VCAM-1 and Monocyte ChemotacticProtein-1 which will attract monocytes to arterial walls and monocytes to macrophages, macrophages take LDL oxidation so full of fat and then foam cell or Foam cell is formed while high levels of antiinflammatory cytokines will inhibit macrophage activity, inhibit chemokine expression and pro-inflammatory cytokines such as IL-17, so IL-10 will inhibit inflammatory reactions in the atherosclerosis process [5], [9], [11].

The occurrence of the inflammatory process in atherosclerosis cannot be separated from the role of cytokines both pro-inflammatory cytokines (IL-17) and anti-inflammatory cytokines (IL-10), an increase in levels of anti-inflammatory cytokines (IL-10) will have an impact on the decrease in the level of proinflammatory cytokines (IL-17) so able to suppress or inhibit the process of atherosclerosis, so the ratio between pro-inflammatory cytokines and antiinflammatory cytokines can also describe the process of atherosclerosis the higher the ratio will increase the chance of atherosclerosis.

The average ratio between IL-17 levels with IL-10 throughout the sample after treatment was $0.114 \pm$ $0.121 \mathrm{pg} / \mathrm{mL}$ with a range of $0.02-0.44 \mathrm{pg} / \mathrm{mL}$. The trend of the ratio between IL-17 levels and IL-10 throughout the sample decreased when compared to the IL-17 level ratio with IL-10 control group with all treatment groups. This study also showed that the ratio between IL-17 levels and IL-10 between treatments had a significant difference $(p<0.05)$. Post hoc tests conducted after treatment on the average ratio between IL-10 rabbits (adjusted) levels in the control group showed that there were significant differences with the treatment group $(p<0.05)$.

Anti-inflammatory cytokines (IL-10) in the treatment group given BSGA extract can inhibit the production of pro-inflammatory cytokines (IL-17), this is consistent with the theory that IL-10 functions as a strong deactivator of pro-inflammatory cytokine synthesis of monocytes/macrophages [6], [12], [13]. Inhibits chemokine expression and pro-inflammatory cytokines (IL-17), inhibits infiltration of neutrophils and macrophages and inhibits inflammatory reactions mediated by cells T [13], [14]. Thus, the proatherogenic effects of IL-17 can be prevented so that tissue damage does not occur, and the number of monocytes that are drawn to the arterial wall has decreased so that the process of foam cell or foam cell formation can be reduced [10]. Thus, the higher the ratio between IL-17 levels and IL-10, the higher the risk of atherosclerosis.

\section{Conclusion}

Apus bamboo shoots extract in various doses has an effect on decreasing the ratio level between pro-inflammatory cytokines (IL-17) and antiinflammatory cytokines (IL-10) in New Zealand White rabbits who given atherogenic diet for 90 days. The average ratio between IL-17 levels with IL-10 throughout the sample before treatment was $0.1274 \pm 0.106 \mathrm{pg} /$ $\mathrm{mL}$ with a range of $0.04-0.41 \mathrm{pg} / \mathrm{mL}$, further become $0.1113 \pm 0.119 \mathrm{pg} / \mathrm{mL}$ with a range of $0.02-0.44 \mathrm{pg} / \mathrm{mL}$ after treatment. That was mean, the higher the dose of apus bamboo shoots extract (520 $\mathrm{mg} / \mathrm{Kg} \mathrm{BW/day)} \mathrm{the}$ more influential the decrease in the ratio between proinflammatory cytokines (IL-17) and anti-inflammatory cytokines (IL-10). Further research can be done with toxicity tests.

\section{References}

1. Virani SS, Alonso A, Benjamin EJ, Bittencourt MS, Callaway CW, Carson AP, et al. Heart disease and stroke statistics-2020 update: A report from the American heart association. Circulation. 2020;141(9):139-596.

PMid:31992061

2. Mulyadi PB. Clinical pathology and Majalah patologi klinik Indonesia dan Laboratorium Medik. J Indones. 2006;21(3):261-5.

3. Galkina E, Ley K. Immune and inflammatory mechanisms of atherosclerosis (*). Annu Rev Immunol. 2009;27:165-97. https:// doi.org/10.1146/annurev.immunol.021908.132620

PMid:19302038

4. Tousoulis D, Oikonomou E, Economou EK, Crea F, Kaski JC. Inflammatory cytokines in atherosclerosis: Current therapeutic approaches. Eur Heart J. 2016;37(22):1723-32. https://doi. org/10.1093/eurheartj/ehv759

PMid:26843277

5. Gradinaru D, Borsa C, lonescu C, Prada GI. Oxidized LDL and NO synthesis--Biomarkers of endothelial dysfunction and ageing. Mech Ageing Dev. 2015;151:101-13. https://doi. org/10.1016/j.mad.2015.03.003

PMid:25804383

6. Quispe-Tintaya W. HHS public access. Physiol Behav. 2017; 176(3):139-48.

PMid:28363838

7. Karakas $M$, Koenig $W$. The role of inflammation in atherosclerosis-an update. Klinikarzt. 2010;39(3):140-6.

8. Soesanto E. Analysis proximate, HCN, antioxidant compounds and antioxidant activities of potential extract as antiatherosclerosis. Med Keperawatan Indones. 2018;1(3):32. https://doi.org/10.26714/mki.1.3.2018.32-45

9. Soesanto E. Uji aktivitas antioksidan ekstrak rebung bambu apus (gigantochloa apus Kurz) terhadap 1,1-diphenyl-2picrylhidrazyl (DPPH). Cendekia J Pharm. 2018;2(2):88-94. https://doi.org/10.31596/cjp.v2i2.22

10. Soesanto E. Antioxidant activity of extracts from Bambusa vulgaris and Gigantochloa apus Kurz Bamboo shoots. Pak J Nutr. 2016;15:580-4. https://doi.org/10.3923/pjn.2016.580.584

11. Iwakura Y, Ishigame H, Saijo S, Nakae S. Functional specialization of interleukin-17 family members. Immunity. 2011;34(2):149-62. https://doi.org/10.1016/j.immuni.2011.02.012 PMid:21349428

12. Ait-Oufella $H$, Taleb $S$, Mallat $Z$, Tedgui A. Recent advances on the role of cytokines in atherosclerosis. Arterioscler 
Thromb Vasc Biol. 2011;31(5):969-79. https://doi.org/10.1161/ atvbaha.110.207415

PMid:21508343

13. Tedgui A, Mallat Z. Cytokines in atherosclerosis: Pathogenic and regulatory pathways. Physiol Rev. 2006;86(2):515-81. https://doi.org/10.1152/physrev.00024.2005

PMid:16601268

14. Soehnlein O. Multiple roles for neutrophils in atherosclerosis Circ Res. 2012;110(6):875-88.

PMid:22427325 